\title{
INOVAÇÃO NO SETOR DE ALIMENTOS: O QUE PENSAM OS CONSUMIDORES SOBRE OS NOVOS PRODUTOS?
}

\author{
Innovation in the food sector: what consumers think about new products? \\ Thelma Lucchese Cheung', Gislayne da Silva Goulart ${ }^{2}$ \\ 'Professora do Programa de Pós-Graduação em Administração \\ ${ }^{2}$ Estudante de mestrado do programa de pós-graduação em administração
}

\section{Resumo}

Neste artigo apresentamos informações sobre as percepções dos consumidores quanto a um produto alimentar inovador, o pão de queijo com cenoura. Consumidores do município de Campo Grande, Mato Grosso do Sul, manifestaram opiniões acerca do produto criado por técnicos do SENAI/MS. Aproximadamente quinhentos homens e mulheres com mais de 18 anos e diferentes níveis socioeconômicos compuseram a amostra dos estudo. $\mathrm{O}$ tratamento estatístico dos dados coletado nos possibilitou compreender que o pão de queijo original é um produto que suscita nos comensais a idéia de rapidez, facilidade no preparo e prazer no consumo. Percebeu-se que falar sobre um pão de queijo diferente do original, por exemplo, o com cenoura, deixou os consumidores indecisos, ansiosos e confusos. Para ser colocado no mercado será necessário que uma comunicação eficiente do produto seja realizada, desviando o caráter natural do produto inovador do mote da sua comunicação.

Palavras chave: Comportamento de consumo alimentar, percepção, produto inovador

\begin{abstract}
This article presents information about consumers' perceptions an innovative food product, the cheese bread with carrots. consumers who live in the city of campo grande were interviewed and asked about the product created by experts from senai / ms. approximately five hundred men and women over 18 years and different socioeconomic levels were included in the sample of the study. the statistical treatment of the data collected allowed us to understand that the original cheese bread is a product that raises the diners the idea of speed, ease of preparation and enjoyment in consumption. it was noticed that talking about a hunk of cheese different from the original, for example, with carrot, left undecided, anxious and confused consumers. to be placed on the market will require effective communication of the product is performed by diverting the natural character of the innovative product of the motto of their communication.
\end{abstract}

Key Words: Food consumption behavior, Perception, Innovative Product 


\section{INTRODUÇÃO}

O Serviço Nacional de Aprendizagem Industrial (SENAI) do estado de Mato Grosso do Sul, através das atividades coordenadas por técnicos e alunos do curso de panificação, destacou-se em um evento nacional denominado INOVA SENAI, no ano de 2012, pela criação de um novo produto, o pão de queijo com cenoura. Desenvolvido na unidade do interior do estado, no município de Dourados, o produto inovador foi apresentado aos participantes do evento, que aconteceu em São Paulo, como uma alternativa mais saudável ao produto de origem mineira. Foram reduzidos $60 \%$ do queijo da receita original e a mesma proporção foi acrescida de polpa de cenoura, gerando uma redução de $40 \%$ de gorduras totais naquele produto. De acordo com a Agência Nacional de Vigilância Sanitária (ANVISA) ${ }^{1}$, a inovação poderia ser categorizada como um produto light, uma vez que dele foram reduzidos mais do que $25 \%$ de um componente calórico, porcentagem preconizada pela agência.

Sabendo-se que a identificação de um mercado-alvo e a construção de uma política de marketing adequada para um produto inovador são tão importantes quanto o seu desenvolvimento, interessou-se em realizar um estudo, na capital do estado do Mato Grosso do Sul, que possibilitasse, aos técnicos do SENAI e outros pesquisadores de uma universidade pública da região, compreender quais as percepções dos consumidores em relação à inovação. Como este artigo é parte de um projeto maior, financiado pelo CNPq, que tem como objetivo definir uma identidade de marca para o pão de queijo com cenoura, os resultados apresentados compreendem, apenas, a parte descritiva do tratamento dos dados que foram coletados em campo. Através destes resultados, serão apresentadas e comentadas as opiniões declaradas por homens e mulheres, com mais de 18 anos, pertencentes a diferentes classes de renda e com diferentes níveis de instrução, acerca do produto inovador. A amostra compreendeu 477 consumidores do município de Campo Grande. Para o tratamento das respostas foram realizadas análises de correspondência múltipla e hierárquica. Para auxiliar a interpretação das análises estatísticas, julgou-se importante apresentar parte do referencial teórico adotado no estudo em que este artigo se insere. Dessa forma, consta a seguir um capítulo breve sobre o referencial teórico, outro

\footnotetext{
${ }^{1}$ Outras informações sobre critérios para classificar alimentos poderão ser encontradas em http://portal.anvisa.gov.br/
}

sobre a metodologia, um penúltimo que apresenta a discussão dos resultados e o de conclusão.

\section{REFERENCIAL TEÓRICO}

A tarefa de compreender as necessidades dos consumidores implica em considerar, além do efeito de variáveis econômicas sobre a produção e a transformação dos alimentos, a ação de outras mais específicas ao ato alimentar. Para isso, julga-se importante compreender quais os papeis desempenhados pelos produtos alimentares aos olhos do consumidor. Aurier e Sirieix (2004; 2009) sugerem quatro papeis principais, chamados pelos autores de função dos alimentos, sendo elas: utilitária, hedônica, simbólica e ética.

\section{I Função Utilitária}

Reúne o conjunto de benefícios mais evidentes associados ao consumo do produto. Trata-se das garantias que os produtos podem oferecer ao consumidor, como equilíbrio nutricional (alimentos sem aditivos, conservantes, acidulantes e etc.), praticidade (embalagens econômicas, embalagens família, minimamente processado, pronto para o consumo e etc.), versatilidade na composição calórica (como versões light e diet e produtos que veiculam imagens de leveza) e caráter funcional (alimentos que se destacam pela maior quantidade que têm de vitaminas, minerais, fibras, carboidratos e etc).

\subsection{Função Hedônica}

As emoções e a satisfação sentidas pelos consumidores durante a experiência do consumo representam os benefícios da função hedônica para o consumidor. O prazer é uma função indissociável do produto alimentar. Um exemplo da força que exerce tal função sobre os comportamentos de consumo é a queda nas vendas de bebidas funcionais que insistem em comunicar o produto, apenas, utilizando um discurso técnico. Inúmeros produtos alimentares são bastante valorizados pelo prazer estético que suscitam (por exemplo, frutas, legumes e óleo de oliva são exemplos clássicos). Esses alimentos servem para ornamentar o espaço das cozinhas. Produtos mais caros que garantem autenticidade ou exclusividade, por exemplo, os vinhos, fazem com que o simples fato de possuí-los gere ao consumidor benefícios positivos no plano emocional. 


\subsection{Função Simbólica}

O produto deve ser interpretado como um meio de comunicar algo para alguém. Mais do que ser útil e provocar prazer, produtos permitem aos indivíduos se comunicar nos meios sociais aos quais frequentam (função de demonstração de pertencimento de um indivíduo a um grupo - cultura, civilização, classe social, tribo). A socialização das refeições faz aparecer o principal benefício do alimento, a convivialidade. O caráter discriminante de certos produtos é justificado por modos de preparo e contextos de consumo. A função de comunicação simbólica do produto pode, também, auxiliar na construção da identidade do consumidor. Pode fazer com que o consumidor se torne "o que ele quer ser" ou "o que ele pensa que os outros querem que ele se torne". Produtos impactam a vida dos consumidores, porque os auxiliam a se adaptar aos seus ambientes. A rejeição de marcas globalizadas e a preferência por consumir produtos de marcas que transmitem códigos diferentes, como um determinado território, amor, autenticidade e exotismo pode ser um exemplo da função de comunicação mencionada.

\subsection{Função Ética e Espiritual}

Ética na etiqueta, produto de divisão, produtos ecológicos são expressões, cada vez mais, valorizadas por grupos de consumidores que não querem ver o prazer da alimentação ser interrompido por crises de consciência, remetidas pela descoberta pela falta de ética incorrida no processo de produção dos seus alimentos. No que concerne à função espiritual, alguns consumidores podem ser mais atraídos por produtos que remetem à religião ou religiosidade.

Levando-se em conta as funções dos alimentos propostas pelos autores supracitados, cabe acrescentar que:

- Consumidores compram produtos para satisfazer necessidades e desejos;

-Os consumidores vêem nos alimentos um conjunto de múltiplos benefícios que esses podem lhes proporcionar, por exemplo, relaxamento, saciedade, equilíbrio nutricional, força física, versatilidade calórica, segurança alimentar e etc.;

-Consumidores podem ter percepções diferentes sobre um mesmo produto alimentar e, com isso, justificar sua compra por diferentes benefícios associados ao alimento. Tais benefícios podem pertencer a mais de um tipo de função do alimento.

No que concerne ao somatório dos benefícios percebidos pelo consumidor, torna-se importante compreender o valor do produto para o consumidor, isto é, saber se os verdadeiros benefícios procurados estão sendo oferecidos e comunicados corretamente ao público-alvo. Consumidores são influenciados pelo que é percebido, por aquilo em que acreditam e julgam ser verdadeiro. Conhecer o segmento mais representativo de determinado produto implica, além da identificação das características dos indivíduos (sociodemográficas, econômicas e culturais), no conhecimento de suas experiências de consumo e nas experiências daqueles que lhes são próximos (NGOBO; JEAN, 2012). Campanhas de comunicação devem ser elaboradas com base nesse conjunto de informações que veicularão o que a marca vai representar ou simbolizar para seu consumidor.

Cabe, por fim, destacar que o conjunto dos benefícios percebidos e dos benefícios procurados pelo consumidor será comparado aos entraves e restrições ao consumo do produto (preço, o acondicionamento no domicílio, o tempo de preparo, os modos de preparo, as maneiras de consumir e etc). Dessa comparação será obtido o valor percebido pelo consumidor. Será através do valor percebido que as campanhas mais eficientes de posicionamento de novos produtos no mercado serão elaboradas (definição dos grandes temas do discurso publicitário, por exemplo, apelo ao território, praticidade, sabor, forma física e autenticidade). Benefícios não valorizados pelos consumidores-alvo representam um custo de produção inútil para a indústria e, por isso, justifica-se, mais uma vez, a importância de se compreender as maneiras como os consumidores percebem os alimentos (Crocco et.al. 2006).

Pensando em estratégia mercadológica, as inovações representam um potencial para empresas agro-alimentares conseguirem se diferenciar em uma época em que se encontram muitos produtos iguais nas prateleiras dos diferentes canais de distribuição.

Segundo Gallen; Panthin-Sohier (2012), o que mais se vê nas prateleiras do mercado são inovações que tangem o produto, ou seja, apresentação de formatos diferentes (por exemplo, tamanhos menores, diferentes formas geométricas e etc) e embalagens que surpreendem (suco kapo, sacos de batata frita com ar, embalagens tetra pack para conservar). Inovações na composição do produto propriamente dito, por exemplo, as melancias menores e sem semente, as melancias quadradas e os camarões azuis, são menos percebidas pelos consumidores como corriqueiras. Assim, poder-se-ia dizer que as inovações no campo da alimentação estão limitadas, principalmente, ao 
papel da comunicação, através das embalagens, sobre as escolhas e preferências dos consumidores, bem como na criação da imagem de uma marca. Os autores afirmam que é recente o interesse das pesquisas de marketing sobre a percepção das inovações em produtos de modo geral e ainda mais recente a atenção que pesquisadores vêm dando às maneiras dos comensais perceberem tais inovações no domínio alimentar.

Quando um produto tradicional passa por inovações em sua composição, o resultado pode ser repulsa ou desconfiança por parte do consumidor. Sentimentos negativos dos consumidores em relação a um produto podem levar atitudes de rejeição à experimentação. Conhecer quais são as características do produto que fazem com que os indivíduos não se sintam motivados em comprá-los e consumi-los representa, para a indústria, um desafio necessário. A inovação e a apresentação de novos produtos para, competir em mercados muito homogêneos em termos de diversificação de produtos ("muitos do mesmo"), são necessárias. Segundo Shararudin et al. (2011), faz-se importante saber como favorecer a aceitação das inovações pelos consumidores, no processo de concepção de um produto. $\mathrm{O}$ que o consumidor pensa sobre o produto? Quais as características que respondem às suas necessidades do momento e os seus desejos de consumo? O que poderia ser modificado no produto para que o consumidor o escolhesse, em detrimento de tantas outras opções de alimentos? Por quê homens e mulheres têm impressões diferentes acerca de uma mesma inovação? Quais as funções que esses produtos inovadores desempenham para consumidores de grupos sociais diferentes?

Pretendendo-se ter pistas sobre as possíveis respostas referentes aos questionamentos ora apresentados, considerando-se os interesses deste artigo à amostra da pesquisa, apresenta-se a seguir o capítulo que trata da metodologia adotada.

\section{METODOLOGIA}

Para a realização da pesquisa, na qual estão inseridos os resultados apresentados neste artigo, foram entrevistados 477 consumidores de pão de queijo tradicional, pertencentes a diferentes classes de renda e tendo declarado níveis de instrução escolar distintos.

Para a composição da amostra, interessou-se mais pela sua característica heterogênea. Todas essas diferenças poderiam tornar possível, a esta pesquisa, escolher critérios de comparação dos comportamentos (por exemplo, quanto às maneiras de perceber o produto inovador), verificar diferentes comportamentos de consumo (segundo suas idades, rendas e níveis de instrução) e identificar consumidoras marginais e potenciais do novo produto.

Para a coleta de dados, optou-se pelo método survey. Malhotra (2004) explica que o método consiste em uma busca de informação, por via de um interrogatório dos entrevistados, quanto aos seus comportamentos, atitudes, percepções, motivações, além das suas características demográficas e de estilo de vida. A condução se deu através de um questionário estruturado e a forma de aplicação foi a entrevista pessoal. O questionário foi elaborado com 52 variáveis, contendo um total de 268 tipos de respostas possíveis (modalidade de variáveis). Tais variáveis refletiram aspectos das posições sócio-econômica e demográfica da amostra, bem como de suas percepções sobre pão de queijo tradicional e sobre um novo produto que será colocado em breve no mercado, o pão de queijo com cenoura.

Considerando-se o interesse deste trabalho em apresentar uma tipologia de consumidores de pão de queijo com cenoura, para tratar os dados coletados e realizar agrupamentos das respostas, optou-se por efetuar uma análise de correspondência múltipla, seguida por uma classificação ascendente hierárquica, análise de cluster, com auxílio do software francês SPAD. A primeira tipologia é referente às percepções dos consumidores quanto ao consumo do produto congelado original. Interessou-se por saber quais as razões que mais motivam consumidores, de diferentes classes sociais, níveis de formação e gênero, em consumir o produto. A diferença dessas análises multivariadas das análises clássicas é que a análise de correspondência múltipla permite avaliar a relação entre um conjunto muito grande de variáveis e a de classificação ascendente hierárquica permite encontrar a tipologia pretendida.

A partir da realização dessas análises, planos fatoriais foram gerados e devem ser interpretados como mapas, onde a localização de cada classe na tipologia implica em semelhanças ou diferenças das escolhas das modalidades de variáveis. Assim, a posição que os indivíduos ocupam nos quadrantes fatoriais e dentro das classes geradas estará muito relacionada à semelhança das suas respostas sobre as variáveis ativas. Cabe ressaltar que para a determinação dos grupos, apenas, foram consideradas as variáveis com maior carga fatorial, ou seja, aquelas que representaram melhor 
o conjunto das respostas.

A análise de correspondência múltipla nos permitiu recuperar os principais tipos de comportamentos e seus determinantes. Para testar o que determinou os diferentes comportamentos declarados, variáveis explicativas dos comportamentos, chamadas de ilustrativas, foram introduzidas no software. Como exemplo dessas variáveis, tem-se: características demográficas e socioeconômicas dos indivíduos e outras variáveis que consideramos igualmente determinantes dos comportamentos humanos, como variáveis socioculturais.

No que concerne aos fatores representados sobre eixos fatoriais (ver figura 2), esses correspondem aos cálculos de distância das modalidades de variáveis por ordem decrescente. Escofier e Pages (1998) e Lebart et al., (1995) reforçam que a métrica do Qui-quadrado ( $\chi 2$ ) permite a comparação de linhas (indivíduos) e colunas (modalidades). Dessa forma, a semelhança entre dois indivíduos foi definida pelo cálculo da distância do Qui-quadrado ( $\chi 2$ ), ou seja, distância entre os seus perfis (modalidades escolhidas) a qual desempenha um papel semelhante ao cálculo do desvio padrão utilizado no estudo de variáveis numéricas ou contínuas.

A análise de dados e dos planos fatoriais foi utilizada para realizar os agrupamentos dos indivíduos em uma tipologia de síntese. Para minimizar o caráter empírico deste método, uma classificação ascendente hierárquica foi, então, efetuada. Assim, os indivíduos foram classificados a partir das distâncias calculadas na análise de correspondência. O número de grupos de indivíduos (classes ou clusters) foi escolhido em função do grau de síntese desejado e da capacidade de explicar o fenômeno estudado. As apresentações dos planos fatoriais e das classes geradas constam no próximo capítulo.

Através do software livre, Iramuteq, foi possível utilizar as questões abertas do questionário, que tratavam especificamente sobre o pão de queijo com cenoura, para realizar duas análises interessantes: a nuvem de palavras (análise lexical simples que organiza de modo gráfico as palavras em função da frequência em que apareceram nos discursos) e a análise de similitude (apresenta as palavras que foram mais correlacionadas, que tiveram mais conexão, que representam mais o modo de pensar do consumidor sobre o produto inovador).

\section{RESULTADOS E DISCUSSÃO}

Como este artigo pretendeu apresentar informações sobre quais seriam as diferentes motivações que os consumidores poderiam ter em relação a um novo produto que será colocado, em breve, no mercado, julga-se conveniente apresentar primeiro o que os consumidores pensam e sentem sobre o consumo da versão original do produto que é amplamente consumida nos estados brasileiros, o pão de queijo congelado. A figura 1 apresenta a tipologia de comportamentos, conseguida com o tratamento dos dados coletados em campo.

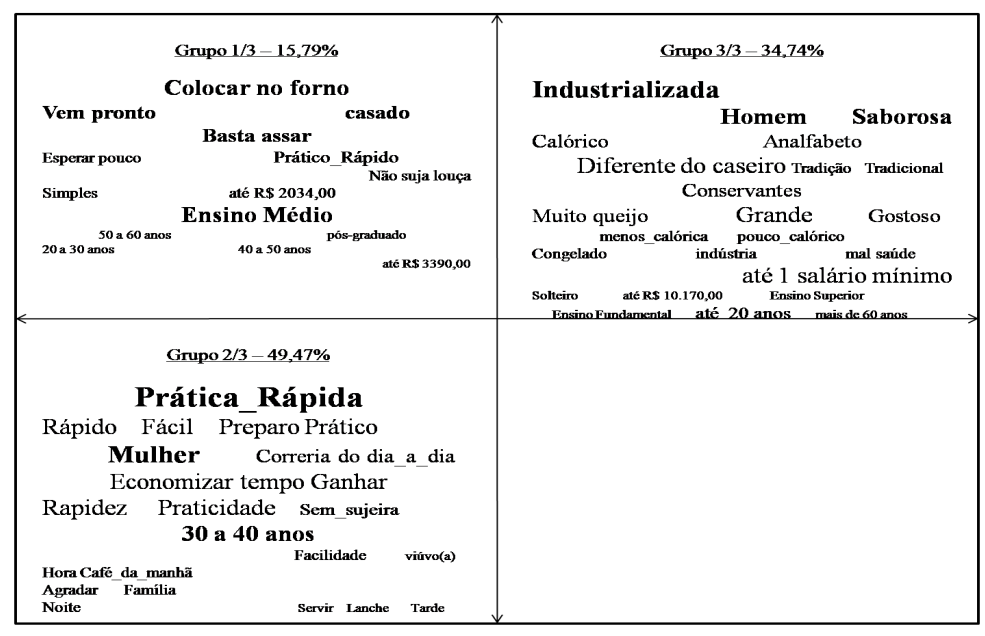

Figura 1 - Tipologia de comportamentos de consumo de pão de queijo congelado. Fonte: Elaborada pelas autoras a partir da pesquisa de campo 
A descrição dos comportamentos de consumo é reveladora de comportamentos interessantes. Evidentemente, o consumo do produto original congelado é interpretado como uma alternativa prática, rápida e que não exige dedicação no preparo. De modo geral, todos concordam que pão de queijo congelado é sinônimo de rapidez e praticidade. Uma comida que agrada a todos, independente de idade, renda e gênero. Interessante, então, é atentar para algumas especificidades do consumo que podem orientar políticas mercadológicas. Descobriu-se que, de modo geral e de modo mais representativo que o conjunto dos respondentes, mulheres mais do que homens, justificam a compra e o consumo do pão de queijo congelado pelas funções hedônica e utilitária do produto. $\mathrm{O}$ fato de não dar trabalho, de não sujar a cozinha, de economizar tempo e de não exigir habilidade culinária no preparo do alimento são justificativas que representam melhor o modo de pensar do gênero feminino da amostra do estudo. Além disso, mulheres, mais do que homens, demonstraram-se preocupadas com as informações nutricionais do produto e com o prazo de validade. As análises não apresentaram fortes correções entre renda e comportamentos de consumo específicos.

Por outro lado, homens de diferentes classes de renda e níveis de instrução, de modo mais significativo do que as mulheres da amostra, justificam o consumo e a compra do produto pelas funções hedônica e simbólica. O prazer em consumir o alimento é evidenciado quando afirmam que, embora seja industrializado, o produto bom deve lembrar o produto caseiro, tradicional, com bastante queijo e com tamanho grande. As palavras "conservantes" e "mal para saúde" aparecem nos quadrantes, porque foram bastante utilizadas para justificar o consumo do produto congelado. Em muitas das falas, os homens afirmam que, embora saibam que é uma comida industrializada, que tem conservante e que, por isso, pode fazer mal para à saúde, o consumo do pão de queijo congelado representa, para eles, sabor, prazer e tradição.

Para compreender quais poderiam ser as motivações em adquirir e consumir uma versão inovadora do produto, o pão de queijo com cenoura, algumas questões lhes foram apresentadas. Deve-se ressaltar que as informações buscadas pela pesquisa sobre esse novo comportamento de consumo são referentes à possibilidade do produto novo provocar: angústia (devido ao não reconhecimento do produto) e ansiedade (por não conseguirem categorizar o novo produto no campo de representações mentais, devido às incongruências em relação ao produto original já categorizado). Interessou-se em saber como a inovação seria entendida pela amostra do estudo, como o processo de criação seria compreendido e interpretado, já que a versão original do produto é amplamente aceita pelos brasileiros. A figura 2 representa, graficamente, a nuvem de palavras encontrada a partir do tratamento dos dados referentes à questão sobre a percepção de um novo produto.

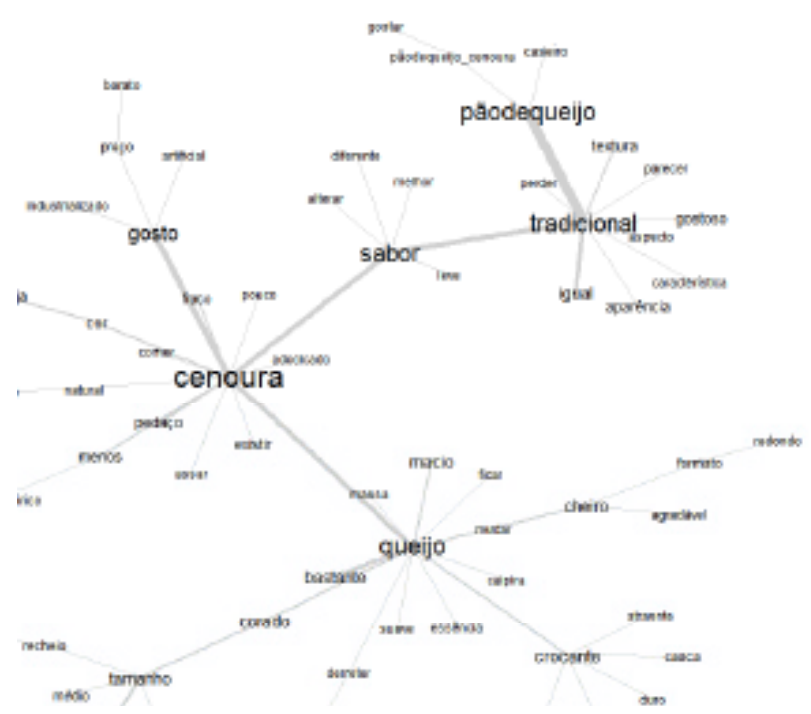

Figura 2 - Nuvem de palavras: significado de pão de queijo com cenoura.

Fonte: Elaborada pelas autoras a partir da pesquisa de campo

As palavras da nuvem representam a percepção ou as maneiras dos comensais perceberem a inovação no domínio alimentar. O arranjo das palavras permite algumas interpretações. Algumas das palavras que mais apareceram nos discursos (maiores e mais hachuradas), sobre as impressões acerca de um pão de queijo com cenoura, não têm conexão com aquelas que foram mencionadas para o pão de queijo original. As expressões "comida industrializada", "comida prática e rápida" e "facilidade no preparo" não representam o imaginário dos indivíduos acerca do produto inovador. Segundo Galen; Panthan-Sohier (2012), quando um produto tradicional passa por inovações em sua composição, os profissionais de marketing e agentes do setor privado devem estar atentos aos desafios que a indústria terá ao ter de comunicar o novo produto para competir em um mercado muito homogêneo em termos de diversificação de produtos ("muitos do mesmo"). Faz-se importante saber como favorecer a aceitação das inovações pelos consumidores, no processo de concepção de um produto. Pensar em inovação em alimentos 
requer um trabalho de questionamentos da função, do uso e do valor do produto alimentar para os consumidores. É a compreensão dessas dimensões que permitirá a realização de inovações que serão mais bem compreendidas pelos comensais.

Deve-se ressaltar que, embora o fator saudável tenha aparecido como justificativa para o interesse dos consumidores sobre o novo produto, este melhor representa as mulheres da amostra. Contudo, de modo geral, entre homens e mulheres, a representação do pão de queijo tradicional e seu aspecto corado, grande, com muito queijo influenciam seus modos de pensar o produto inovador. Em muitas falas os consumidores ressaltaram que um pão de queijo com cenoura somente poderá ser bom se "tiver muito queijo, se ficar bem corado e se tiver o gosto do pão de queijo tradicional". A categorização do produto tradicional é mais bem representada pelas funções simbólica e hedônica. $\mathrm{O}$ aspecto utilitário que o produto inovador traz como mensagem principal, que é comunicada (menos queijo ou gordura e mais nutrição com a cenoura, suas fibras e vitaminas), parece não chamar a atenção dos consumidores da amostra.

Galen; Panthan-Sohier (2012) entendem que a inovação só é interessante quando interfere sobre as representações. Elementos visuais devem difundir mensagens que favorecem a formação de um conjunto de imagens mentais, ou representações mentais, as quais participam das maneiras de pensar dos consumidores em relação aos produtos. É dessa forma que consumidores fazem inferência sobre o gosto, sobre a qualidade dos alimentos. De acordo com os autores, em produtos em que a marca é um item quase ausente (assim como foi identificado para o caso do pão de queijo tradicional, já que os consumidores da amostra do estudo não se lembraram de marcas que compravam), mas principal indicador de qualidade, inovações e design são totalmente pertinentes. Deve-se centrar as informações sobre a receita, os aspectos visuais, o destaque ao sabor (provocar surpresa) e sobre a textura. Chamar atenção para nostalgia e autenticidade pode ser um caminho. Inovações devem dar sentido aos produtos, tornando-os inteligíveis e compreensíveis no imaginário dos comensais.

A figura 3 , originada a partir de uma análise de similitude, a qual permite realizar interpretações das representações sociais de um objeto estudado, reitera as afirmações ora realizadas sobre as percepções dos consumidores entrevistados quanto ao pão de queijo com cenoura. As conexões entre as palavras hachuradas mais fortes (mais representativas dos discursos) devem ser compreendi- das como o modo com que são ancoradas pelos consumidores, ou seja, arranjadas na memória.

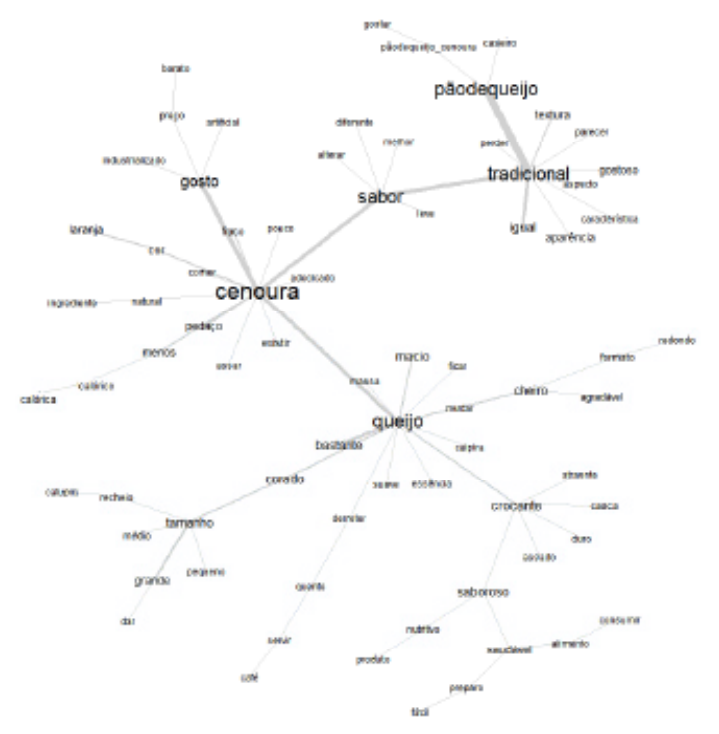

Figura 3 - Similitude: significado de pão de queijo com cenoura. Fonte: Elaborada pelas autoras a partir da pesquisa de campo

Interessante à indústria e ao SENAI, enquanto criador do produto em processo de solicitação de patente, é observar as conexões das palavras utilizadas pelos consumidores para explicar o que chama mais atenção e justificaria a compra e o consumo do produto original (por exemplo, sabor, textura, queijo, tamanho, tradição e rapidez) e o que justificaria a compra e o consumo do produto inovador (menos calórico, adocicado, laranja e natural). Faz-se, por fim, necessário afirmar que a análise de similitude mostra o produto original, ancorado na biblioteca de imagens mentais dos consumidores, através de representações mais ligadas ao prazer. Conforme já foi mencionado, antes que a indústria coloque o novo produto no mercado, este trabalho sugere que ações eficientes de comunicação sejam propostas enquanto política de marketing. Pensar em inovação em alimentos requer um trabalho de questionamentos da função, do uso e do valor do produto alimentar.

\section{CONCLUSÕES}

Para a amostra do estudo realizado no município de Campo Grande, pão de queijo é sinônimo de comida rápida, fácil de preparar, que não exige habilidades culinárias e que não faz sujeira na cozinha. Essas informações represen- 
tam importantes pistas para a indústria comunicar tanto o produto original quanto novas versões ou produtos semelhantes, mas inovadores. Descobriu-se, também, que pão de queijo é um alimento consumido por comensais com diferentes níveis de renda, escolaridade e gênero. A ampla aceitação do produto original poderá comprometer a aceitação do produto inovador, pão de queijo com cenoura, já que foi percebida uma atitude mais negativa do que positiva pelos consumidores entrevistados. $\mathrm{O}$ componente afetivo da atitude não foi despertado pelo produto novo. Percebeu-se um esforço cognitivo dos consumidores para fazer uma avaliação ou emitir opiniões acerca de um pão de queijo com cenoura. Considera-se que haverá necessidade de comunicá-lo de modo lúdico, caso a indústria pretenda distribuir o produto no mercado. Variedade, novidade e diferenciação podem representar bem palavras que descrevam inovação. Porém, para o produto em questão, julga-se que a comunicação deverá ser centrada sobre o aspecto hedônico que o consumo poderá provocar. Preocupação estética e o prazer sensorial deverão representar o mote da comunicação. A substituição do ingrediente queijo por cenoura provocou, de modo geral, uma desconfiança por parte dos consumidores quanto ao gosto, textura e, principalmente, quanto ao prazer que um produto como esse poderá proporcionar aos comensais.

\section{REFERÊNCIAS}

AURIER, P.; SIRIEIX, L. Le marketing des produits agroalimentaires (2a edição). Paris: Dunod, 2004.

AURIER, P.; SIRIEIX, L. Le marketing des produits agroalimentaires (3a edição). Paris: Dunod, 2009.

CROCCO, L.; TELLES, R.; GIOIA, R.M.; ROCHA, T.; STREHLAU, V.I. Decisões de marketing: os 4Ps. São Paulo: Saraiva, 2006.

GALLEN, C.; PANTHIN-SOHIER, G. Design et marketing des produits alimentaires: quelles sont les perspectives d'innovation?Lemna, EA 4272, Université de Nantes, 2012.

NGOBO, P.V. ; JEAN, S. Does store image influence demand for organic store brands? Journal of Retailing and Consumer Services, 621-628, 2012.
Escofier, B., \& Pages, J. (1998). Analyses factorielles simples et multiples: objectifs, méthodes et interprétation. Paris: Dunod.

Malhotra, N. K. (2004) Pesquisa de Marketing: Uma Orientação Aplicada. 4. ed. São Paulo: Bookman.

Lebart, L., Morineau, A., \& Piron, M. (1995). Statistique exploratoire miltidimensionelle. Paris: Dunod.

SHARARUDIN, M. R.; BIN ISMAIL, A. S; WAN MANSOR, S.; ELIAS, S.J;JALIL, M.A.; OMAR, M.W. Innovative Food and Its Effects toward Consumers'Purchase Intention of Fast Food Product. Canadian Social Science, vol.7, n.1, 2011. 